\title{
Systemic Risk and Centrality Revisited: The Role of Interactions
}

HOSSEIN ASGHARIAN, DOMINIKA KRYGIER \& ANDERS VILHELMSSON

KNUT WICKSELL WORKING PAPER 2019:1

\section{Working papers}

Editor: F. Lundtofte The Knut Wicksell Centre for Financial Studies

Lund University School of Economics and Management

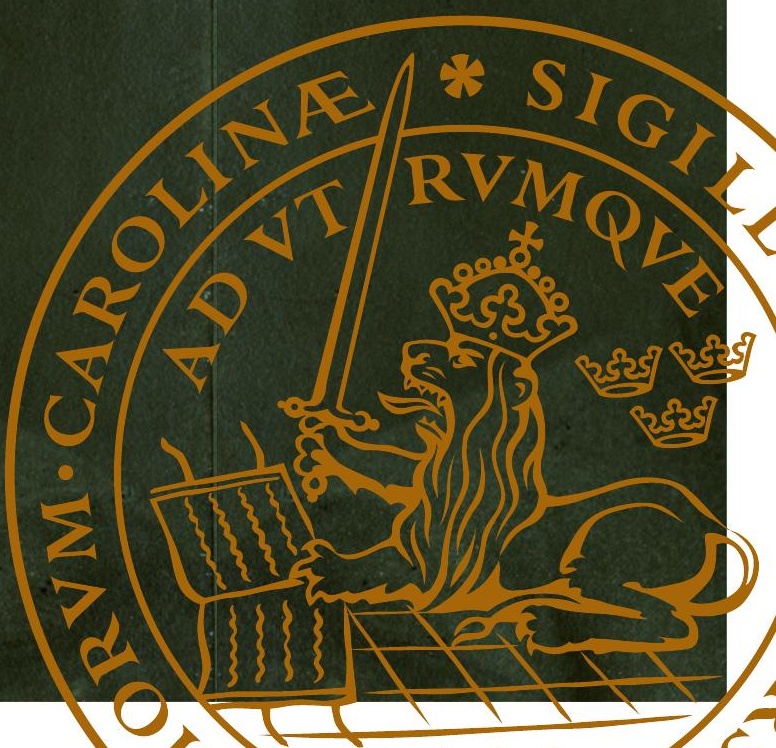





\title{
Systemic Risk and Centrality Revisited: The Role of Interactions"
}

\author{
Hossein Asgharian, Lund University ${ }^{+}$ \\ Dominika Krygier, Lund University ${ }^{++}$ \\ and \\ Anders Vilhelmsson, Lund University ${ }^{+++}$
}

March 3, 2019

\begin{abstract}
We suggest that banks contribute extensively to systemic risk only if they are both "risky" and centrally placed in the financial network. To calculate systemic risk we apply the $\triangle \mathrm{CoVaR}$ measure of Adrian and Brunnermeier (2016) and measure centrality using detailed US loan syndication data. In agreement with our conjecture our main finding is that centrality is an important determinant of systemic risk but primarily not by its direct effect. Rather, its main influence is to make other firm specific risk measures more important for highly connected banks. A bank's contribution to systemic risk from a fixed level of Value-at-Risk is about four times higher for a bank with two standard deviations above average centrality compared to a bank with average network centrality. Neglecting this indirect moderation effect of centrality severely underestimates the importance of centrality for "risky" banks and overestimates the effect for "safer" banks.
\end{abstract}

KEYWORDS: systemic risk, network centrality, loan syndication, $\triangle \mathrm{CoVaR}$, quantile regression

\footnotetext{
+ Hossein Asgharian, Department of Economics, Lund University, Box 7082, 22007 Lund, Sweden. Hossein.Asgharian@nek.lu.se

++ Dominika Krygier, Department of Economics, Lund University, Box 7082, 22007 Lund, Sweden. Dominika.krygier@nek.lu.se

+++ Anders Vilhelmsson, Department of Economics, Lund University, Box 7082, 22007 Lund, Sweden. Anders.vilhelmsson@nek.lu.se
} 


\section{Introduction}

Systemic risk is the risk of a crisis in the financial sector with consequential negative spill-over effects to the real economy. For understanding and managing systemic risk it is important to understand both macro and micro determinants of systemic risk. Macro determinants focus on the overall structure of the financial system whereas the micro approach focuses on the marginal contributions of individual actors to systemic risk. Our paper is primarily focused on the micro level but combines it with the macro level by studying the banking network. Our basic idea is simple. We suggest that a bank's centrality should not be considered a separate cause of systemic risk, rather we suggest that centrality affects how much the "riskiness" of a bank contributes to systemic risk. Statistically this means we should treat centrality as a moderator variable. We therefore investigate how the contribution to systemic risk of standard bank level risk measures vary depending on the centrality of the bank. We suggest that "risky" banks contribute extensively to systemic risk only if they are centrally placed in the financial network.

Somewhat surprisingly, the impact on systemic risk from the interaction effect of centrality and bank characteristics has not been investigated before. Though in isolation both the impact of firm characteristics is studied (Adrian and Brunnermeier, 2016; Saunders et al., 2018; Brunnermeier et al., 2019) and that of network centrality (Cai et al., 2018; Martinez-Jaramillo et al., 2014). The treatment of centrality and other bank risks as separate and independent sources of systemic risk is also reflected in current regulation of systemic risk (BCBS, 2018).

To calculate systemic risk, we use the $\triangle \mathrm{CoVaR}$ measure of Adrian and Brunnermeier (2016) and centrality is obtained using the network of banks participating in the loan syndication market. The paper most closely related to ours is that of Cai et al. (2018), who also calculate an interconnectedness measure from syndicated loans and use it to explain different measures of systemic risk, including $\triangle$ CoVaR. Our paper differs from Cai et al. (2018) in several aspects: Cai et al. (2018) measure commonality of asset holdings whereas our paper considers network connections between banks. Hence, our paper complements Cai et al. (2018) by focusing on the centrality of a bank rather than on balance sheet overlap. Further and most importantly Cai et al. (2018) do not interact firm characteristics with their commonality measure, instead treating it as a separate source or risk. 
The data on loan syndication is obtained from the Thomson Reuters DealScan database that provides historical information on the terms and conditions of deals in the global commercial and industrial loan market. It has been used by, for example, Ivashina et al. (2015) and Sufi (2007). We consider two banks to be linked when they participate in the same loan syndicate and calculate six different centrality measures based on the loan syndication data.

Using panel data regressions to explain $\triangle \mathrm{CoVaR}$ our main finding is that centrality is an important determinant of systemic risk contribution but primarily not by its direct effect. Rather, its main influence is to make Value-at-Risk much more important for highly connected firms. A bank's contribution to systemic risk from Value-at-Risk is about four times higher for a bank with two standard deviations above average centrality compared to a bank with average network centrality. Neglecting this indirect moderation effect of centrality severely underestimates the importance of centrality for "risky" banks and overestimates the effect for "safer" banks. Our results are robust to different specifications of centrality and still remain after simultaneously allowing also size to act as a moderator variable.

The structure of the paper is as follows: section two introduces the concept of systemic risk in terms of its meaning, measurement, regulation and related literature. Section three presents the data and discusses the variable choices made in our models. In section four we proceed by introducing the methodology of $\Delta \mathrm{CoVaR}$, network theory and network centrality in the loan syndication market. Section five presents and discusses our main results and contributions, and section six concludes.

\section{Systemic risk}

Systemic risk is the risk of a crisis in the financial sector with resulting negative spillover effects to the real economy. The important features are that all or parts of the system are affected at the same time, due to a disruptive event, and that it has damaging effects to the real economy, in terms of negative externalities. For an excellent recent review of the topic see Benoit et al. (2017). 


\subsection{Regulation}

Since 2012, The Basel committee on Banking Supervision (BCBS) has ranked the world's largest financial institutions ${ }^{1}$ according to their systemic importance. The current method described in BCBS (2018) uses five categories: size, interconnectedness, substitutes or financial institution infrastructure, crossjurisdictional activity, and complexity. These five categories are computed from underlying indicators and the total "systemic importance score" is calculated as an equally weighted average from the five categories. Details of calculations as well as potential problems with the current methodology, are discussed in Benoit et al. (in press). The 29 banks with the highest systemic risk score are subject to additional capital requirements calculated based on which of five "buckets" they end up in. The additional charges range from $1 \%$ additional equity to risk weighted capital up to $3.5 \%$ in the highest bucket. The "bucket list" for 2018 is available in FSB (2018).

\subsection{Related literature}

Three interrelated fields of research have emerged within the area of systemic risk. The first concerns the measurement of systemic risk. Systemic risk measures attempt to quantify the extent of the loss resulting from shocks hitting the system, i.e. to gauge the potential increase in tail-comovement stemming from financial distress in the system. Therefore, these measures must be designed in a way that they capture the systemic nature of risk and shock transmission of firms co-operating in a system, or network, i.e. the cross-sectional component. There exist several measures trying to take this into account. One of these is the $\triangle \mathrm{CoVaR}$ of Adrian and Brunnermeier (2016). $\triangle \mathrm{CoVaR}$ is a market-based measure of systemic risk that tries to capture the crosssectional tail-dependency between a firm and the whole financial system. It is directional and asks the question how much does system wide risk increase should an individual firm be in financial distress. The conditioning can also be reversed in order to answer questions such as which actors are most at risk should a crisis occur. $\Delta \mathrm{CoVaR}$ is described in more detail under the "Method" section of this paper.

Other empirical measures based on publicly available data are for example SRISK proposed in Brownlees and Engle (2016) and the distressed insurance premium

\footnotetext{
${ }^{1}$ Total exposure $>200$ billion Euro, with exposure measured as in the leverage ratio framework of BIS (2013).
} 
(DIP) by Huang et al. (2012). Other systemic risk measures include the marginal expected shortfall (MES) by Brownlees and Engle (2012), systemic expected shortfall (SES) by Acharya et al. (2012) and component expected shortfall (CES) by Banulescu and Dumitrescu (2015). The main difference between the mentioned measures is the conditioning event, i.e. how "distress" or a "tail event" is defined.

A natural next step after measuring systemic risk is to relate the risk estimate to possible firm-level determinants of the degree of systemic importance among financial institutions, and subsequently study the predictive ability of these determinants in order to mitigate, or even prevent, a future financial crisis. This field is the most well tilled, most likely due to the need to incorporate systemic risk into financial regulation after the financial crisis but also because market based econometric methods, like $\Delta \mathrm{CoVaR}$, are silent about what causes a firm to contribute to systemic risk. The aim of this part of the literature is thus to predict the future systemic risk contribution of a firm. The three most common firm-specific characteristics that have been found to explain systemic importance of individual financial institutions are size (Pais and Stork, 2011; Black et al., 2016), leverage (Brunnermeier at al., 2019), Kaufman and Scott, 2003) and VaR (Adrian and Brunnermeier, 2016). Additional characteristics such as degree of non-interest income and nonperforming loans are shown in De Jong et al. (2015) and Brunnermeier et al. (2019) to predict systemic risk contribution.

The third field deals with interconnectedness or the network perspective of systemic risk. Risk spillovers among firms are a result of both direct linkages between banks, in terms of interbank transactions (Allen and Gale, 2000), and commonality of asset holdings, in terms of holding assets with similar risk exposures (Cai et al., 2018). Network theory is used as the main tool to estimate and quantify spillover effects. This area is less explored and was initiated by Allen and Gale (2000) who study how the banking system responds to contagion under different system network structures and further explored in Billio et al. (2012). The network analysis literature deals primarily with networks and their structure, and is concerned with the joint loss distribution of all market participants, see for example Hautsch et al. (2014). Cont et al. (2012) study the mechanism of shock propagation when bank size and degree of interconnectedness is taken into account. They find that institutions tend to be more systemically important if they have large interbank exposures, and also that an institution's position in the (particular) network plays an important role when it comes to its systemic significance. To briefly summarize the section on interconnectedness, one could say that in addition 
to the traditional "too-big-to-fail" view, a "too-central-to-fail" equivalent is included in the ongoing debate on systemic risk.

Our paper is most closely related to Cai et al. (2018), who also study the interconnectedness of banks and systemic risk. Similarly, they use the database DealScan as the source of their loan syndication data. However, while they measure commonality of asset holdings our paper complements Cai et al. (2018), by focusing on the risk spillover source that results from direct linkages between banks. Based on an interconnectedness measure that considers the "distance" (similarity) between two banks' syndicated loan portfolios, they find that banks with similar asset holdings contribute more to systemic risk and that this effect is exacerbated during recessions. They also find that interconnectedness is positively related to size and diversification level as well as with various systemic risk measures such as $\Delta \mathrm{CoVaR}, \mathrm{SRISK}$ and DIP.

Our paper is related to all three research fields, but contributes most to the second and third by being the first study to investigate if firm specific variables such as VaR, non-performing loans and non-interest income vary in importance depending on the centrality of the firms. We are not only investigating whether centrality contributes to systemic risk directly, but also its moderating effect e.g. if one unit of VaR contributes more to systemic risk for a firm that is central than it does for a non-central firm.

\section{Data}

This paper combines data from several different sources. Macrodata from FRED and stock return data from CRSP is used to compute $\triangle \mathrm{CoVaR}$. Our centrality measure is based on loan level information from DealScan and firm specific information is taken from Compustat/Capital IQ. We define our initial sample as the 1823 financial institutions ${ }^{2}$ in Adrian and Brunnermeier (2016), we can match 738 of these companies to DealScan using the matching from Chava and Roberts (2008) and Forssbaeck et al. (2018). Out of these companies 264 have information about the syndicate structure of the loan which we need to calculate the centrality measure which can be compared to Cai et al. (2018) who have data for 38 companies.

\footnotetext{
${ }^{2}$ Adrian and Brunnermeier (2016) are using PERMNOS which is a security and not a company identifier so companies with dual class shares are included twice in their sample, we exclude duplicates.
} 


\subsection{Data for $\triangle C o V a R$}

We obtain daily stock return data from CRSP for the time period 1995 to 2016.

The same state variables are used as in Adrian and Brunnermeier (2016) as a means to capture tail risk dependence over time and make $\triangle \mathrm{CoVaR}$ time varying. The state variables are obtained from FRED (The Federal Reserve Bank of St. Louis Economic Data) and consist of

I. The change in the three month yield.

II. The change in the slope of the yield curve. This is the yield spread between the 10 year treasury bill rate and the 3 month bill rate.

III. TED spread (three month LIBOR minus three month secondary market treasury bill rate).

IV. Change in the credit spread between Moody's Baa-rated bonds and the ten-year treasury rate.

V. Weekly market CRSP value weighted return.

VI. Weekly real estate sector return (SIC 65-66) in excess of the financial sector return (K. French data).

VII. Equity volatility (22 day rolling SD of daily CRSP equity market return).

Variables II and IV are assumed to capture time variation in the tails of returns, variables V and VI are used as controls for equity market returns, and I, III and VII are factors or indicators to capture short-term liquidity risk (III), future economic activity and inflation (I) and uncertainty and investor sentiment (VII).

\subsection{Data for centrality measures}

In order to calculate a centrality measure for each lender we need to have data on something that represents "bank-to-bank-activities". We use data on syndicated loans provided by the Thomson Reuters DealScan database to measure interbank activities. Specifically, we measure how central a bank is in the syndicated loan market. We believe this is a good proxy for interbank connections because it is more likely that a bank with a lot of connections on the loan syndication market also has a lot of connections (with the same counterparties) on the interbank market. Another reason for using the loan syndication market is its size. For example, in the US, the loan syndication market alone is bigger than the public debt and equity markets together (Cai et al., 2018). By looking at loan syndication activities we can also study patterns 
of balance sheet overlap when it comes to banks' loan portfolios. Cai et al. (2018) show that there is a tendency of banks to choose the same syndicate partners over time. This is consistent with the idea that banks within the same syndicate group also engage in other business transactions apart from syndication.

DealScan provides information on the terms and conditions of deals in the global commercial loan market, including the loan syndication market and has been used in, for example, Ivashina et al. (2015) and Sufi (2007). The database contains more than 300,000 loans over the period from 1985 to 2016, most of the loans are syndicated. A syndicated loan is a type of loan offered by a number of banks or financial institutions, and normally is coordinated by one bank called as lead arranger and then other banks are participants in the syndicate.

\subsection{Data for accounting variables}

Based on the literature review in section 2.3 a set of variables is chosen as the determinants for explaining and predicting systemic risk contribution. These variables consist of VaR, leverage, size, the ratio of non-performing loans to total assets, noninterest income to interest income and lastly our centrality measure which is described in detail in section 4.2. A brief description of each variable and its economic importance is presented below. Exact item identifiers for CapitalIQ can be found in the appendix.

I. Value-at-Risk (VaR): $\mathrm{VaR}$ is a widely-used risk measure in both theory, practice and as a regulatory tool. It calculates the maximum potential loss that we may expect for a firm $i$ with some probability $q$, over a holding period of $n$ days. Details of calculation are given in section 4.1.

II. Size: Size is considered one of the standard firm-specific systemic risk determinants in the systemic risk literature. We measure size by the log of market capitalization Large banks are different from small banks not only in asset values, but larger banks also tend to engage more in non-lending activities, generate more income from non-interest income, hold less risk-weighted capital, have higher leverage, have less deposit funding and are more organizationally complex. We naturally expect a large bank to contribute more to systemic risk than a small bank.

III. Leverage ( $L E V)$ : We define leverage as total assets divided by the book value of equity. Leverage tells us something about the solvency of a firm and is one 
of the standard firm-specific systemic risk determinants in the literature. Leverage is expected to increase a firm's contribution to systemic risk. A high leverage ratio increases the likelihood of a firm going into insolvency by insolvencies of other firms earlier in the transmission chain who transmit losses forward.

IV. Non-performing loans (NPL): NPL is a loan in default or a loan close to default. NPL to total assets as a firm specific risk factor is important to consider because high levels of NPLs may hold down credit growth and economic activity by deterring banks from undertaking one of their core tasks; providing credit. That is, the variable tells us something about the loan portfolio quality of banks and accounts for realized credit risk. The relationship between the contribution to systemic risk and the NPL rate is therefore expected to be positive.

V. Non-interest income (NII): Non-interest income to interest income is a (ratio) variable that takes into account how "non-traditional" a bank is, in the sense that the bank is engaged in non-interest generating activities such as investment banking, venture capital, securitization, fees and derivatives trading. These activities are often deemed more risky than traditional lending and hence one would expect a positive relationship between non-interest income and systemic risk. However, the variable also captures, to some extent, diversification strategies of firms and the expected sign of the variable is therefore ambiguous.

\section{Method}

In this section, we first describe the method we use to estimate CoVaR (section 4.1). We then give a detailed description of our centrality measures (section 4.2). Finally, we present the regression model to find the factors that can explain CoVaR (section 4.3).

\subsection{CoVaR}

$\mathrm{CoVaR}$ is defined as the $\mathrm{VaR}$ of an institution, conditional on another institution being in financial distress. CoVaR measures what happens to a system's VaR when one specific institution is in financial distress, as measured by its own VaR. $\Delta$ CoVaR instead answers the questions of how the VaR of the system changes if a particular institution is in financial distress. 
We begin by recalling the definition of $\mathrm{VaR}$ of a firm $i$ which is simply the maximum potential loss that we can expect for firm $i$ with some probability $q$, over a holding period of $n$ days. In other words, we are looking for the $q$-quantile in the return distribution. Common choices of $q$ are $1 \%$ and $5 \%$, we focus on $1 \%$ as in Brunnermeier et al. (2019).

$$
\operatorname{Pr}\left(\mathrm{X}^{\mathrm{i}} \leq \operatorname{VaR}_{\mathrm{q}}^{\mathrm{i}}\right)=\mathrm{q}
$$

We can now define CoVaR of a firm $j$ conditional on some event $\mathbb{C}\left(X^{i}\right)$ of a firm $i$ (may it be firm $i$ being in financial distress) in the following way

$$
\operatorname{Pr}\left(X^{j} \leq \operatorname{CoVaR}_{q}^{j \mid \mathbb{C}\left(X^{i}\right)} \mid \mathbb{C}\left(X^{i}\right)\right)=q
$$

Thus, $\operatorname{CoVaR} R^{j \mid \mathbb{C}\left(X^{i}\right)}$ is defined by the $\mathrm{q}^{\text {th }}$ quantile of the conditional probability distribution above. The event $\mathbb{C}\left(X^{i}\right)$, causing firm $i$ to be in financial distress, is normally defined as that firm having reached its $q \%$-VaR level (i.e. $X^{i}=V a R_{q}^{i}$ ), but it could be any negative event that makes firm $i$ financially distressed. In this paper, the conditioning event $\mathbb{C}\left(X^{i}\right)$ is the one stated above. CoVaR is hence the $\mathrm{VaR}$ of some firm $j$ given that another firm $i$ is financially distressed. Usually one defines $j$ to be the financial system, in order to calculate a firm $i$ 's contribution to systemic risk in the system. This contribution of firm $i$ to systemic risk in the system $j$, termed $\Delta \mathrm{CoVaR}$, can be calculated as follows

$$
\Delta \operatorname{CoVaR}_{\mathrm{q}}^{\mathrm{j} / \mathbb{C}\left(\mathrm{X}^{\mathrm{i}}\right)}=\operatorname{CoVaR}_{\mathrm{q}}^{\mathrm{j} \mid \mathrm{X}^{\mathrm{i}}=\operatorname{VaR}_{\mathrm{q}}^{\mathrm{i}}}-\operatorname{CoVaR}_{\mathrm{q}}^{\mathrm{j} \mid \mathrm{X}^{\mathrm{i}}=\operatorname{VaR}_{\mathrm{q}=0.5}^{\mathrm{i}}}
$$

The above classification allows us to calculate the contribution of firm $i$ to the systemic risk of the financial system $j . \Delta \mathrm{CoVaR}$ simply represents the difference between the $\mathrm{VaR}$ of the financial system conditional on if firm $i$ is in distress or not. Not being in distress is defined as firm $i$ operating in "normal times", i.e. being at its 50\%-VaR level.

$\mathrm{CoVaR}$ is estimated using quantile regression on weekly equity returns following Adrian and Brunnermeier (2016). A quantile regression of the returns of a firm $i\left(X^{i}\right)$ on a constant $\alpha$ gives the firm's q\%-VaR, which is simply the estimate of the $q^{\text {th }}$ quantile of $X^{i}$

$$
\begin{gathered}
X_{q}^{i}=\alpha_{q}^{i}+\varepsilon_{q}^{i} \\
\operatorname{VaR}_{q}^{i}=\hat{\alpha}_{q}^{i}
\end{gathered}
$$


Similarly, by running a quantile regression of system $j$ returns $\left(X^{j}\right)$ on a firm's $i$ returns $\left(X^{i}\right)$ plus a constant $\alpha$, we find the $\mathrm{CoVaR}$ of the system $j$, given that firm $i$ is at its q-\% VaR level:

$$
\begin{gathered}
X_{q}^{j}=\alpha_{q}^{i}+\beta_{q}^{i} X^{i}+\varepsilon_{q}^{i} \\
\operatorname{CoVaR}_{q}^{j \mid X^{i}=V a R_{q}^{i}}=V a R_{q}^{j} \mid V a R_{q}^{i}=\hat{\alpha}_{q}^{i}+\hat{\beta}_{q}^{i} V a R_{q}^{i}
\end{gathered}
$$

Again, CoVaR is hence the fitted value of $X_{q}^{j}$ given that $X^{i}=V a R_{q}^{i}$ for a pre-specified quantile $q$. Firm $i$ 's contribution to systemic risk is then given by the following:

$$
\begin{gathered}
\Delta \operatorname{CoVaR}_{q}^{j \mid X^{i}=V a R_{q}^{i}}=\left(\hat{\alpha}_{q}^{i}+\hat{\beta}_{q}^{i} \operatorname{VaR} R_{q}^{i}\right)-\left(\hat{\alpha}_{0.5}^{i}+\hat{\beta}_{0.5}^{i} \operatorname{VaR} R_{0.5}^{i}\right) \\
=\hat{\beta}_{q}^{i}\left(\operatorname{VaR}_{q}^{i}-\operatorname{VaR}_{0.5}^{i}\right)
\end{gathered}
$$

Note that $\operatorname{VaR}_{0.5}^{i}$ is the median of the return distribution and denotes the "normal" state of the institution. The last equality in equation (6) is proved in appendix B of Benoit et al. (2013). Further assuming that the median return of institution $i$ is close to zero we get

$$
\Delta \operatorname{CoVaR}{ }_{q}^{j \mid X^{i}=\operatorname{VaR}}{ }_{q}^{i} \approx \hat{\beta}_{q}^{i} \operatorname{VaR}_{q}^{i}
$$

with the coefficient $\hat{\beta}_{q}^{i}$ being the linear projection coefficient of the market return, on the bank return. Since $\hat{\beta}_{q}^{i}$ is firm specific there is no strong cross-sectional dependence between the $\mathrm{VaR}$ and $\triangle \mathrm{CoVaR}$ (shown in figure 1 of Adrian and Brunnermeier, 2016) however for a given firm $\triangle \mathrm{CoVaR}$ is proportional to VaR with the proportionality coefficient $\hat{\beta}_{q}^{i}$ being firm specific. Figure 6 in Benoit et al. 2013 shows the perfect correlation between $\mathrm{VaR}$ and $\triangle \mathrm{CoVaR}$ over time for Bank of America ${ }^{3}$.

The above estimations only construct constant estimates, i.e. we only observe the average contribution of systemic risk over the chosen time period and nothing about how the contribution is changing over time. In order to construct a time-varying series of VaRs, CoVaRs and $\Delta \mathrm{CoVaRs}$ that captures the time variation in the distribution of $X^{i}$ and $X^{j}$ we need to estimate the conditional return distribution as a function of state variables. That is, we need to assume that equity returns depend on a set of macro variables that are acknowledged to capture the tail risk dependence and expected

\footnotetext{
${ }^{3}$ The correlation will still be one when time variation is induced by state variables as in Brunnermeier et al. (2016), Adrian and Brunnermeier (2019) and this in this paper. If a DCC-GARCH model instead is used the correlation will be close to but not exactly one (Benoit et al. 2013).
} 
returns over time. These macro variables are presented in the data section. The estimation follows Adrian and Brunnermeier (2016).

\subsection{Centrality measures}

We use network theory to identify and quantify centrality. The aim of network analysis is to describe the structure of networks by focusing on the relationships that exist between all or a set of actors in the network. The main goal is to identify influential, or central, actors. Networks are important to analyze in the setting of systemic risk because they can facilitate and amplify the transmission of shocks, initially often minor shocks, which partly depends on how the network is constructed.

A network is made up of points, denoted nodes, with lines that connect them, called edges. We represent the network matrix $\mathbf{M}$ by an $n \times n$ network matrix where $n$ represents the number of nodes in the network. We use two alternative approaches to construct the network matrix. In the first approach we define $M_{i j, t}$ as the total number of loan facilities that $i$ and $j$ are jointly involved in at time $t$. In the second approach, we construct the so-called adjacency matrix, where the element, $M_{i j, t}$, of the network matrix takes the value one if $i$ and $j$ are jointly involved in at least in one facility at time $t$ and it takes the value zero otherwise. The network matrix is symmetric since if $i$ is connected to $j$, then clearly $j$ is connected to $i$. We also use two alternative approaches to determine if two firms are connected at time $t$ : the first approach uses the entire duration of the facility in which the two lenders are jointly involved and the second approach only considers the start date of the facility.

There are several measures of centrality that are based on network theory (for a detailed description, see for example Newman, 2008). We adapt the eigenvector centrality measure that gives a score (ranking) for each node (actor) that depends on both the number and quality of the node's connections. ${ }^{4}$ The aim is to compute the centrality of an actor as a function of the number of its neighbors, i.e. its connections in the network, as well as the importance of its neighbors in the network.

We construct a network of all the US lenders involved in these facilities. The network is constructed for a total of 7740 banks and financial firms and includes our initial sample of banks as well as all the US lenders that participated at least once in

\footnotetext{
${ }^{4}$ Mathematical details of eigenvector centrality can be found in for example Bonacich (2007), Bonacich and Lloyd (2001) and Newman (2008).
} 
the same syndicated loans as the banks in our sample. We use the start and the end date of the facilities to construct a network matrix in each quarter. More specifically, for each quarter $t$ we construct a matrix with 7740 rows and columns in which the element in row $i$ and column $j$ is equal to the number of the common outstanding syndicated loan of bank $i$ and bank $j$ in that quarter, (i.e. when $t$ is equal or larger than the starting date and equal or smaller than the end date of the syndicated loan in which both $i$ and $j$ are involved). The eigenvector associated with the largest eigenvalue of the network matrix in each quarter is used as the measure of centrality of banks in that quarter. We construct such a centrality score for all the 7740 banks and then use the score related to banks included in our sample as an independent variable in our regression analysis.

In total, we construct six centrality measures $(\mathrm{CM})$ :

- CM1: $M_{i j, t}$ is equal to the number of facilities that $i$ and $j$ are jointly involved in period $t$, for all $t$ from start date to the end date of each facility. CM1 for lender $i$ at quarter $t$ is equal to the element $i$ of the eigenvector associated with the largest eigenvalue of the network matrix $\mathbf{M}$ in each quarter.

- CM2: The network matrix is defined as in CM1, but assumes that the link between two lenders exponentially decreases over time after the starting date of the facility contract. More specifically, we specify the total number of connections bank $i$ has with all other banks, each quarter until maturity, but allow connections to get weaker over time. We use an exponentially decreasing function to avoid negative value for a link

$$
M_{i j, t}=\sum_{f \in F_{i j, t}} \exp \left(-g Q_{f, t}\right)
$$

where, $g$ is the smoothing parameter (selected as 0.1 for a smooth decrease) and $Q_{f t}$ is the number of quarters at time $t$ from the starting date of the facility (syndicated loan) $f$ in which $i$ and $j$ jointly participate, such that

$$
0 \leq Q_{f t} \leq \text { duration of facilty } f
$$

We sum over all the facilities that $i$ and $j$ are jointly involved in period $t$, which is denoted by $F_{i j, t}$. CM2 for lender $i$ at quarter $t$ is equal to the element $i$ of the eigenvector associated with the largest eigenvalue of the network matrix $\mathbf{M}$ in each quarter.

- CM3: The network matrix is defined as in CM1, but we only consider the facility start date to define the link between two lenders in the network matrix. For example, 
if bank $i$ and $j$ initiate the syndicate in 2015Q1, this connection is not included in 2015Q2 even though the syndicate is still ongoing. A connection is visible only the quarter it is initiated. CM3 for lender $i$ at quarter $t$ is equal to the element $i$ of the eigenvector associated with the largest eigenvalue of the network matrix $\mathbf{M}$ in each quarter.

- CM4: This measure is based on the adjacency matrix, where the element in row $i$ and column $j$ is set to 1 if bank $i$ and bank $j$ has at least one common outstanding syndicated loan in that quarter. More formally the adjacency matrix is defined:

$$
M_{i j, t}=\left\{\begin{array}{cc}
1 & \text { If } i \text { and } j \text { are jointly part of any syndicate in period } t \\
& \text { facility start date } \leq t \leq \text { facility end date } \\
0 & \text { Otherwise }
\end{array}\right.
$$

This measure does not account for the number of connections the two banks have in each period $t$. CM4 for lender $i$ at quarter $t$ is equal to the element $i$ of the eigenvector associated with the largest eigenvalue of the network matrix $\mathbf{M}$ in each quarter.

- CM5: The network matrix is defined as an adjacency matrix, as in CM4, but we only consider the facility start date to define the link between two lenders in the network matrix. CM5 for lender $i$ at quarter $t$ is equal to the element $i$ of the eigenvector associated with the largest eigenvalue of the network matrix $\mathbf{M}$ in each quarter.

- CM6: In all the five centrality measures above, we use the network matrix to define the relative centrality or importance of each lender. In CM6, we consider being a lead arranger of loans as the measure of centrality and importance of a lender in the network. Lead arrangers collect a group of lenders to jointly finance a syndicated loan, they negotiate the price and non-price loan terms and usually retain the largest part of the loan. CM6 for lender $i$ at quarter $t$ is equal to the number of facilities in each period $t$ in which each lender has the role as Lead Arranger of the facility. ${ }^{5}$

Note that all the measures above are calculated based on the total number of 7740 lenders and all the facilities that these lenders have been involved in. We then extract the measures for our sample of 264 firms. The table below shows a summary of the five measures, CM1 to CM5, that are based on the network matrix.

\footnotetext{
${ }^{5}$ We classify a lender as a lead arranger if its role in DealScan is defined as administrative agent, agent, arranger, book-runner, coordinating arranger, lead arranger, lead bank, lead manager, and mandated arranger. We exclude the cases with no lead arranger or with multiple lead arrangers. This information is then cross-checked with the field "LeadArrangerCredit" in DealScan. For a lead arranger this field should be "Yes".
} 


\begin{tabular}{|l|l|l|}
\hline Duration & Matrix with the \# of links & Adjacency matrix \\
\hline Start to end date of facility & $\begin{array}{l}\text { CM1 } \\
\text { CM2 (decreasing) }\end{array}$ & CM4 \\
\hline Start date of facility & CM3 & CM5 \\
\hline
\end{tabular}

\subsection{Explaining ACoVaR: The Regression Model}

Market based econometric methods such as $\triangle \mathrm{CoVaR}$ measure an individual firm's contribution to systemic risk but are mute about the firm-specific causes of systemic risk. To understand systemic risk both from a scholarly and regulatory perspective it is therefore useful to find the causes of systemic risk. We do so by using firm specific (accounting based) variables that can predict the systemic risk of a firm one quarter ahead in time. This is also done in Adrian and Brunnermeier (2016) and Brunnermeier et al. (2019). In contrast to these papers, we are primarily interested in investigating whether firm specific variables such as VaR, NPL and NII vary in importance depending on the centrality of the firm. That is, we are not only investigating if centrality by itself contributes to systemic risk but rather if e.g. one unit of $\mathrm{VaR}$ contributes more to systemic risk for a firm that is centrally placed in the bank network. We do so by interacting centrality with previously found determinants of systemic risk.

We estimate panel regressions with year fixed effects and cluster standard errors on the firm level in all specifications. The most general specification is given by

$$
\Delta \operatorname{CoVaR}_{i t}=\alpha_{y}+\boldsymbol{\beta}^{\prime} \boldsymbol{X}_{\boldsymbol{i}}+\gamma \operatorname{Cent}_{i t}+\boldsymbol{\psi}^{\prime}\left(\boldsymbol{X}_{i \boldsymbol{t}} \cdot C M_{i, t}\right)+\varepsilon_{i t},
$$

with $\boldsymbol{X}_{\boldsymbol{i}}$ being a $k \times 1$ vector of our firm specific variables, $C M_{i, t}$ being one of the six different centrality measures for firm $i$ at quarter $t, \alpha_{y}$ is the year fixed effect for quarter $t$ in year $y, \boldsymbol{\beta}$ and $\boldsymbol{\psi}$ are $k \times 1$ coefficient vectors and $\gamma$ is a scalar. In the regressions all variables are standardized to have standard deviation of unity to make the coefficient estimates directly comparable. Note that the almost prefect within firm correlation between $\mathrm{VaR}$ and $\triangle \mathrm{CoVaR}$ means it is not possible to estimate these panel regressions with firm fixed effects and simultaneously include VaR as an explanatory variable. Adrian and Brunnermeier (2016) include VaR and exclude firm fixed effects whereas Brunnermeier et al. (2019) exclude VaR but include firm fixed effects. Since we are 
interested in the effect of $\mathrm{VaR}$ and its interaction with centrality we include VaR and exclude firm fixed effects.

\section{Results and discussion}

We start the analysis by the descriptive statistics of the variables used in the study. We then discuss the results of the univariate and multivariate regressions in sections 5.2 and 5.3, respectively. Section 5.4 investigates if the effects of the variables on CoVaR are different in normal and recession periods. Finally, we analyze the role of size as a moderator variable in section 5.5.

\subsection{Descriptive statistics}

The correlations between all the variables are reported in Table 1. Except $\Delta \mathrm{CoVaR}$ all the variables are one-period lagged. The values are based on the average of measures for each lender. The correlations are in general very high between the first five measures, particularly between CM1, CM2 and CM3. We can conclude that using different durations of facilities to define the network does not affect the relative importance of the lenders. The correlations between CM6, which is defined based on the number of facilities with the lead arranger role, and the other five measures varies between 0.5 and 0.8 . Interestingly all centrality measures are positively correlated with $\triangle \mathrm{CoVaR}$ and size but negatively correlated with $\mathrm{VaR}$ with the exception of CM6 which has a small positive correlation with VaR. Further the correlation between size and centrality while positive is just around 0.2-0.3, depending on the centrality measure, indicating that size and centrality are distinct measures.

\section{[Insert Table 1 here]}

Table 2 shows the summary statistics of the variables included in the regression analysis. The distribution of all the centrality measures, and in particular CM6, are skewed to the right with many firms having close to zero importance and a few lenders being very central. $8 \%$ of the lenders have CM1 equal to zero for all the periods (it is not shown in the table), which happens if they are the sole lender of a facility, while for CM6, 50\% of the lenders have zero value over the entire period, i.e. they have never been lead arranger of a facility, while ten lenders have around $90 \%$ of the total number of the lead arranger roles within our sample. Citigroup and Bank of America have the largest average number of facilities with lead arranger role, i.e. average per quarter of 
1105 and 1101 facilities, respectively. The most central firms based on CM1 are in general the firms that often take the role as lead managers of facilities, but this is not always the case. For example, out of the ten firms that have the highest centrality score only six firms are among the top ten lead arrangers.

\section{[Insert Table 2 here]}

It is interesting to mention that the mean values of CM6 is 3.633 for the entire sample of 7740 lenders (not reported in the table), and 17.668 for our sample. This shows that the firms included in our sample are on average more important than the excluded firms. More specifically, our selected sample of 264 lenders has $16 \%$ of the number of the lead arrangers in the total sample of 7740 lenders, which considering that these lenders comprise only $3 \%$ of the total lenders used to construct the network, confirms the relative importance of the banks in our sample. This share has increased from around $8 \%$ (1995) to above $25 \%$ (2016). This increase is more apparent after the financial crisis. The increase partly depends on the selection in our sample (that we use companies that have return data for at least 50 weeks to estimate CoVaR) and partly on the market becoming more concentrated, particularly after (and due to) the financial crisis.

Figure 1 illustrates a network matrix for the last quarter of our sample, 2016Q4. We use an adjacency matrix to avoid having several lines between each two nodes. We use the start and the end date of the facilities to construct this matrix, i.e. two firms are assumed to be connected from start date to the end date of each facility. Please note that the figure only shows the links between the 264 firms used in our main study, while the centrality measures are based on the link between all 7740 lenders. The figure shows that financial companies such as Citigroup, Bank of America, Wells Fargo, PNC Finance and Northern trust are involved in many syndicated loans in this quarter.

[Insert Figure 1 here]

In Figure 2, we show the persistence in centrality, i.e. the probability of belonging to the top $10 \%$ group in subsequent periods. We use our main centrality measure, CM1 in this figure. We see that the probability of being central (being in top 10\%) in two successive periods is quite high (mostly between $90 \%$ to 100\%). The values vary slightly for different periods (note that quarter 1 corresponds to 1995Q1 and Quarter 88 corresponds to $2016 \mathrm{Q} 4)$. The probability that a firm belongs to the $10 \%$ most central 
firms during the whole sample is just below $2 \%$, which means that we should expect that around five firms belong to this group. In fact, the following four firms belong to top $10 \%$ CM1 in all the 88 quarters: Citigroup, Merrill Lynch, Northern Trust and PNC Fin.

[Insert Figure2 here]

\subsection{Univariate results}

Table 3 shows results from regressing $\triangle \mathrm{CoVaR}$ on $\mathrm{CM} 1$ and on the factors, one at a time, together with their interaction. The reason for only using one control at a time is primarily because of a relatively large number of missing values e.g. VaR is available for 13,099 company quarters whereas non-performing loans is only available for 5,542 company quarters. Note that when an interaction term is included in the regression the interpretation of individual coefficients is as intercept terms for the interaction, since all regressors are standardized the individual coefficients are to be interpreted as the change in $\triangle \mathrm{CoVaR}$ for a one standard deviation increase in the variable when the interacted variables are taking on their mean values.

[Insert Table 3 here.]

Both $\mathrm{VaR}$ and leverage have positive and significant interactions with centrality showing that they both contribute more to systemic risk for centrality placed banks. For leverage, we can see that for a bank with average centrality, leverage has no significant effect on systemic risk. Size and non-interest income both have negative interactions with centrality. The expected effect of non-interest income on systemic risk is ambiguous. Brunnermeier et al. (2019) find that the systemic risk contribution is higher for banks with a higher non-interest income to interest income ratio. However, whether non-interest income is beneficial or detrimental to individual firm risk has been studied with mixed results. For example, Fraser et al. (2002) conclude that a higher level of non-interest income activities is related to more volatile returns, and De Jonghe (2010) finds that systemic risk increases monotonically with non-interest income. Noninterest income is however also indicative of an overall diversification strategy of the firm and could therefore decrease systemic risk since it gives the firm a more diversified portfolio from other revenue producing activities. However, banks with low NII have a more traditional business models, less proprietary trading and are therefore 
safer. The negative interaction we find between size and centrality is however more surprising but when we turn to the multivariate results this effect will disappear.

\subsection{Multivariate results}

Table 4 shows the multivariate results when all factors and their interactions with the centrality measure are included simultaneously. A very clear result is a positive and significant interaction effect between Value-at-Risk and centrality across all different measures of centrality. For our main measure of centrality, CM1, only size, Value-atRisk and centrality appear to significantly affect $\Delta \mathrm{CoVaR}$. Size has a direct impact on $\Delta \mathrm{CoVaR}$ whereas centrality primarily acts as a moderator variable, making the impact of Value-at-Risk much more pronounced for centrally placed firms. The coefficients of the year fixed effects capture differences in CoVaR over time that are not explained by any of the variables. These coefficients (not reported in the table) are not significantly different from zero except during the financial crisis 2008-2009 and during 2010-2011.

\section{[Insert Table 4 here.]}

Figure 3 shows the marginal effect of our five firm specific variables on $\Delta \mathrm{CoVaR}$ for different levels of centrality using CM1. The interaction effect is only significant for $\mathrm{VaR}$ which we will therefore focus on. For the least central firms, the effect of a one standard deviation increase in $\mathrm{VaR}$ on $\Delta \mathrm{CoVaR}$ is around $0.1^{6}$, each standard deviation increase in centrally increases this effect by 0.163 so for a firm that has a centrally two standard deviations above the mean, the effect of $\mathrm{VaR}$ on $\triangle \mathrm{CoVaR}$ is more than four times bigger at $0.09+2 \times 0.163=0.416$. The results are generally very consistent between different measures of centrality.

[Insert Figure 3 here.]

Figure 4 shows the centrality and Value-at-Risk of the 15 largest financial institutions in our sample as measured by market capitalization. Firms in the top right quadrant have above average centrality and above average Value-at-risk, their contribution to systemic risk has previously been underestimated since the positive interaction between centrality and $\mathrm{VaR}$ is ignored. This is the case for Citigroup, Bank of America and Morgan Stanley. Firms that have below average centrality and VaR

\footnotetext{
${ }^{6}$ The minimum value for the standardized CM1 is -0.167 so

$\frac{\partial \Delta \mathrm{CoV} a R}{\partial V a R}=0.122+0.163 \times C M 1=0.122+0.163 \times-0.167=0.095$
} 
and hence have their contribution to systemic risk overestimated when ignoring interactions include Goldman Sachs, Blackrock and American express. The firm with the highest VaR is Fannie Mae but its estimated contribution to CoVaR is small since it also has the lowest centrality.

[Insert Figure 4 here.]

\subsection{The effect of recessions}

In Table 5 we investigate how the results differ between recessions and normal times. We use two dummy variables in the regression, one for NBER recession periods and one for normal (expansion) periods. All the variables and their interactions are multiplied by these dummies. The direct effect of size becomes much more important during recessions increasing from 0.46 to 0.82 . The interaction between $\mathrm{VaR}$ and centrality is a bit higher during recession, but the measurement is so imprecise that the results becomes insignificant. During normal times the interaction between VaR and centrality is still significant with a $p$-value $<0.01$. During recession there is also a negative interaction between non-interest income and centrality which is not present during normal times. This result sheds some light on the previously conflicted finding on the dual role of non-interest income making a bank safer because of diversification benefits but at the same time potentially riskier because of the risk of e.g. proprietary trading losses. Our results show that diversified banks (high non-interest income) contribute less to systemic risk than other types of banks but this difference only exists during recessions and only for centrally placed banks.

[Insert Table 5 here.]

The marginal effects of the variables from this regression model are presented in Figure 5. The effect of $\mathrm{VaR}$ on CoVaR is significantly positive, as well as increasing, for all levels of centrality, both in recession and normal periods.The marginal effect of size is positive and significant for different level of centrality, but it is decreasing with increase in centrality. The marginal effect of leverage on CoVaR is positive, but it is only significant during the normal period and for firms with high centrality values. In contrast NII shows to have negative and significant marginal effect on CoVaR, during the recession period. The effect is significant for all firms except those with very low value of CM1.

[Insert Figure 5 here.] 
The effect of $\mathrm{VaR}$ on $\mathrm{CoVaR}$ is significant both on recession and normal period. To obtain a better understanding of the relative importance of this variable over time, we use a multiple regression similar to that shown in Table 4 but multiply dummy variable for each year with both $\mathrm{CM} 1$ and $\mathrm{VaR}$ as well as with their interaction terms. We plot the marginal effects of VaR for different years in Figure 6. The marginal effect is generally higher during the financial crisis than other periods, but the difference is much more pronounced for centrally placed firms.

[Insert Figure 6 here.]

\subsection{Size and Centrality}

In Table 6 we investigate if also size has the role of a moderator variable increasing the effect of other bank specific variables such as leverage and the share of non-performing loans. Model 2 shows that size and centrality seem to work in similar ways, the effect of $\mathrm{VaR}$ on $\Delta \mathrm{CoVaR}$ is much higher for large firms as evidenced by the significant interaction between $\mathrm{VaR}$ and size. This effect persists when we simultaneously allow for interactions with both centrality and size (specification 3 ).

Although size and centrality are related, they are not capturing exactly the same thing as shown by the significant interaction between both centrality and VaR and size and VaR when included simultaneously in model 3. Contrary to De Jonghe et al. (2015) and in agreement with Saunders et al. (2018) we do not find that non-interest income reduces the systemic risk contribution of large banks. Finally, in model 4 we investigate what effect being both large and centrally placed has by estimating three-way interactions. The interesting result from the three-way interactions is that leverage has a positive effect on CoVaR only for firms that are both large and centrally placed.

[Insert table 6 here.]

\section{Conclusion}

The aim of this paper is to examine if firm specific characteristics found to explain systemic risk matter more or matter less when the centrality of firms is taken into account. Traditionally, the impact of firm characteristics has been assumed to be independent of how central the firm is and current regulation of systemic risk treat centrality and firm specific risk factors as separate sources of systemic risk. Our main 
finding is that centrality is an important determinant of systemic risk but primarily not by its direct effect. Rather its main influence is as a moderator variable, making other firm specific risk measures such as $\mathrm{VaR}$ and non-interest rate income much more important for central banks. Neglecting this indirect effect severely underestimates the importance of centrality for "risky" (high VaR) banks and overestimates the effect for "safer" banks. Current regulation on systemic risk takes centrality into account since it is one of the five categories used for calculating systemic importance, but it does so just as a standalone component. By giving each of the five categories that contribute to systemic risk equal weight, current regulation cannot capture that the importance of firm characteristics varies with centrality. 


\section{References}

Acharya, V., Engle, R., and Richardson, M. (2012). Capital shortfall: A new approach to ranking and regulating systemic risks. The American Economic Review, 102(3), 5964.

Adrian, T., and Brunnermeier, M. K. (2016). CoVaR. The American Economic Review, 106(7), 1705-1741.

Allen, F., and Gale, D. (2000). Financial contagion. Journal of political economy, 108(1), 1-33.

Banulescu, G. D., and Dumitrescu, E. I. (2015). Which are the SIFIs? A Component Expected Shortfall approach to systemic risk. Journal of Banking and Finance, 50, 575-588.

BCBS (2018). Global systemically important banks: updated assessment methodology and the higher loss absorbency requirement, Bank for International Settlements.

Benoit, S., Colletaz, G., Hurlin, C., and Perignon, C., (2013) A Theoretical and Empirical Comparison of Systemic Risk Measures, HEC Paris Research Paper No. FIN-2014-1030. Available at SSRN:http://dx.doi.org/10.2139/ssrn.1973950.

Benoit, S., Colliard, J. E., Hurlin, C., and Pérignon, C. (2017). Where the risks lie: A survey on systemic risk. Review of Finance, 21, 109-152.

Benoit, S., Hurlin, C., and Pérignon, C. (in press). Pitfalls in systemic-risk scoring. Journal of Financial Intermediation.

Billio, M., Getmansky, M., Lo, A. W., and Pelizzon, L. (2012). Econometric measures of connectedness and systemic risk in the finance and insurance sectors. Journal of Financial Economics, 104(3), 535-559.

Black, L., Correa, R., Huang, X., and Zhou, H. (2016). The systemic risk of European banks during the financial and sovereign debt crises. Journal of Banking and Finance, 63, 107-125.

Bonacich, P. (2007). Some unique properties of eigenvector centrality. Social networks, 29(4), 555-564.

Bonacich, P., and Lloyd, P. (2001). Eigenvector-like measures of centrality for asymmetric relations. Social networks, 23(3), 191-201.

Brownlees, C. and Engle, R.F., 2016. SRISK: A conditional capital shortfall measure of systemic risk. The Review of Financial Studies, 30(1), pp.48-79.

Brownlees, C.T. and Engle, R., 2012. Volatility, correlation and tails for systemic risk measurement. Available at SSRN, 1611229.

Brunnermeier, M. K., Dong, G. N., and Palia, D. (2019). Banks' non-interest income and systemic risk. Working paper, Princeton University.

Cai, J., Eidam, F., Saunders, A. and Steffen, S., 2018. Syndication, interconnectedness, and systemic risk. Journal of Financial Stability, 34, pp.105-120.

Chava, S., and Roberts, M. R. (2008). How does financing impact investment? The role of debt covenants. The Journal of Finance, 63(5), 2085-2121. 
Cont, R., Moussa, A. and Santos, E.B. (2012). Network structure and systemic risk in banking systems. Available at:

https://papers.ssrn.com/sol3/papers.cfm?abstract_id=1733528, 2017-03-14

De Jonghe, O. (2010). Back to the basics in banking? A micro-analysis of banking system stability. Journal of financial intermediation, 19(3), 387-417.

De Jonghe, O., Diepstraten, M., and Schepens, G. (2015). Banks' size, scope and systemic risk: What role for conflicts of interest?. Journal of Banking and Finance, 61, S3-S13.

Forssbaeck, J. and Lundtofte, F. and Strieborny, M. and Vilhelmsson, A. (2018) Does the 'Foreignness' of Bank Loans Matter? Evidence from a New Dataset (November 15, 2018). Available at SSRN

Fraser, D. R., Madura, J., and Weigand, R. A. (2002). Sources of bank interest rate risk. Financial Review, 37(3), 351-367.

FSB. (2018). 2018 list of global systemically important banks (G-SIBs). Available at http://www.fsb.org/wp-content/uploads/P161118-1.pdf

Hautsch, N., Schaumburg, J., and Schienle, M. (2014). Financial network systemic risk contributions. Review of Finance, 19 (2): 685-738

Huang, X., Zhou, H., and Zhu, H. (2012). Systemic risk contributions. Journal of financial services research, 42(1-2), 55-83.

Ivashina, V., Scharfstein, D. S., and Stein, J. C. (2015). Dollar funding and the lending behavior of global banks. The Quarterly Journal of Economics, 130(3), 1241-1281.

Martinez-Jaramillo, S., Alexandrova-Kabadjova, B., Bravo-Benitez, B., and Solórzano-Margain, J. P. (2014). An empirical study of the Mexican banking system's network and its implications for systemic risk. Journal of Economic Dynamics and Control, 40, 242-265.

Newman, M. E. (2008). The mathematics of networks. The new palgrave encyclopedia of economics, 2(2008), 1-12.

Pais, A., and Stork, P. A. (2011). Bank size and systemic risk. European Financial Management. 19(3), 452-469

Saunders, A., Schmid, M., and Walter, I. (2018). Non-Core Banking, Performance, and Risk. SSRN

Sufi, A. (2007). Information asymmetry and financing arrangements: Evidence from syndicated loans. The Journal of Finance, 62(2), 629-668. 
Table 1. Correlations matrix of the variables

This table presents the correlations between all variables used in our analysis. Except $\Delta \mathrm{CoVaR}$ all the variables are one-period lagged. The correlations correspond to averages of cross-sectional correlations computed each year during the period 1995Q1-2016Q4.

\begin{tabular}{lcccccccccccc}
\hline & ACoVar & VaR & SIZE & LEV & NPL & NII & CM1 & CM2 & CM3 & CM4 & CM5 & CM6 \\
\hline ACoVar & 1.000 & & & & & & & & & & & \\
VaR & 0.230 & 1.000 & & & & & & & & & & \\
SIZE & 0.423 & -0.156 & 1.000 & & & & & & & & & \\
LEV & -0.007 & 0.198 & 0.068 & 1.000 & & & & & & & & \\
NPL & -0.053 & 0.339 & -0.220 & 0.215 & 1.000 & & & & & & & \\
NII & 0.171 & -0.037 & 0.381 & -0.108 & -0.046 & 1.000 & & & & & & \\
CM1 & 0.137 & -0.036 & 0.251 & 0.011 & -0.048 & 0.188 & 1.000 & & & & & \\
CM2 & 0.142 & -0.034 & 0.254 & 0.009 & -0.039 & 0.188 & 0.967 & 1.000 & & & & \\
CM3 & 0.144 & -0.032 & 0.252 & 0.007 & -0.033 & 0.187 & 0.901 & 0.963 & 1.000 & & & \\
CM4 & 0.179 & -0.062 & 0.339 & 0.057 & -0.072 & 0.278 & 0.714 & 0.685 & 0.644 & 1.000 & & \\
CM5 & 0.188 & -0.045 & 0.293 & 0.024 & -0.054 & 0.276 & 0.771 & 0.804 & 0.834 & 0.778 & 1.000 & \\
CM6 & 0.115 & 0.009 & 0.195 & -0.006 & -0.017 & 0.083 & 0.792 & 0.774 & 0.713 & 0.489 & 0.560 & 1.000 \\
\hline
\end{tabular}




\section{Table 2. Sample statistics}

This table presents summary statistics for all variables used in our analysis. Except $\triangle \mathrm{CoVaR}$ all the variables are one-period lagged. Definitions and exact item identifiers of these variables are found in the appendix. The variables are on a quarterly basis and cover the period 1995Q1-2016Q4.

\begin{tabular}{lccccccc}
\hline & Mean & Std & Kurtosis & Skewness & Minimum & Maximum & \# of obs \\
\hline ACoVar & 0.030 & 0.021 & 9.099 & 1.598 & -0.035 & 0.241 & 13219 \\
VaR & 0.122 & 0.076 & 14.574 & 2.609 & 0 & 1.248 & 13099 \\
SIZE & 7.074 & 2.5 & 3.247 & -0.951 & -7.929 & 12.588 & 9699 \\
LEV & 10.24 & 6.18 & 5.213 & 1.657 & 1.27 & 38.661 & 9591 \\
NPL & 0.009 & 0.013 & 10.832 & 3.144 & 0 & 0.077 & 5542 \\
NII & 0.406 & 0.578 & 19.27 & 4.173 & 0.031 & 3.821 & 5859 \\
CM1 & 0.004 & 0.024 & 132.789 & 10.485 & 0 & 0.439 & 20880 \\
CM2 & 0.004 & 0.026 & 138.878 & 10.807 & 0 & 0.45 & 20880 \\
CM3 & 0.004 & 0.026 & 140.413 & 10.894 & 0 & 0.461 & 20880 \\
CM4 & 0.005 & 0.014 & 25.1 & 4.525 & 0 & 0.134 & 20880 \\
CM5 & 0.004 & 0.018 & 44.49 & 6.312 & 0 & 0.219 & 20880 \\
CM6 & 17.668 & 173.503 & 403.193 & 17.915 & 0 & 5120 & 20880 \\
\hline
\end{tabular}


Table 3. Regression results with only centrality and one factor at a time

This table shows results from regressing $\triangle \mathrm{CoVaR}$ on $\mathrm{CM} 1$ and on our factors one at a time together with their interaction. Definitions and exact item identifiers of these variables are found in the appendix. The variables are on a quarterly basis and cover the period 1995Q1-2016Q4.

\begin{tabular}{lccccc}
\hline & VaR & SIZE & LEV & NPL & NII \\
\hline CM1 & $-0.083^{* * *}$ & $0.285^{* * * *}$ & -0.112 & $0.231^{* * *}$ & $0.338^{* * * *}$ \\
& 0.019 & 0.081 & 0.124 & 0.051 & 0.067 \\
X & $0.126^{* * *}$ & $0.434^{* * *}$ & -0.025 & $-0.168^{* * *}$ & $0.200^{* * *}$ \\
X.CM2 & 0.009 & 0.055 & 0.064 & 0.035 & 0.052 \\
& $0.171^{* * *}$ & $-0.049^{* * *}$ & $0.157^{* *}$ & -0.055 & $-0.105^{* * *}$ \\
Year dummy & 0.013 & 0.013 & 0.079 & 0.034 & 0.039 \\
Adj. $R$-square & Yes & Yes & Yes & Yes & Yes \\
\# of obs. & $16 \%$ & $35 \%$ & $18 \%$ & $20 \%$ & $20 \%$ \\
\hline
\end{tabular}




\section{Table 4. Multivariate regression results}

The table shows the multivariate results when all factors and their interactions with the centrality measure are included simultaneously in the regression. For sake of comparison, we show the results for all the six different centrality measures. Definitions and exact item identifiers of the variables are given in the appendix. The variables are on a quarterly basis and cover the period 1995Q1-2016Q4.

\begin{tabular}{|c|c|c|c|c|c|c|}
\hline & CM1 & CM2 & CM3 & CM4 & CM5 & CM6 \\
\hline \multirow[t]{2}{*}{$\mathrm{CM}$} & -0.228 & -0.206 & -0.245 & -0.032 & 0.109 & -0.341 \\
\hline & 0.327 & 0.327 & 0.338 & 0.406 & 0.373 & 0.351 \\
\hline \multirow[t]{2}{*}{ VaR } & $0.122^{* *}$ & $0.121^{*}$ & $0.119^{*}$ & $0.106^{*}$ & $0.119^{*}$ & $0.128^{* * *}$ \\
\hline & 0.062 & 0.062 & 0.062 & 0.062 & 0.061 & 0.062 \\
\hline \multirow[t]{2}{*}{ SIZE } & $0.516^{* * *}$ & $0.514^{* * *}$ & $0.511^{* * *}$ & $0.529^{* * *}$ & $0.505^{* * *}$ & $0.526^{* * * *}$ \\
\hline & 0.094 & 0.095 & 0.095 & 0.105 & 0.098 & 0.091 \\
\hline \multirow[t]{2}{*}{ LEV } & -0.021 & -0.020 & -0.021 & -0.010 & -0.018 & -0.020 \\
\hline & 0.039 & 0.039 & 0.039 & 0.040 & 0.039 & 0.038 \\
\hline \multirow[t]{2}{*}{ NPL } & -0.042 & -0.043 & -0.043 & -0.047 & -0.044 & -0.044 \\
\hline & 0.039 & 0.039 & 0.039 & 0.039 & 0.038 & 0.038 \\
\hline \multirow[t]{2}{*}{ NII } & 0.009 & 0.016 & 0.014 & -0.009 & 0.010 & -0.008 \\
\hline & 0.046 & 0.045 & 0.043 & 0.052 & 0.049 & 0.035 \\
\hline \multirow[t]{2}{*}{$\mathrm{VaR} \times \mathrm{CM}$} & $0.163^{* * *}$ & $0.158^{* * *}$ & $0.160^{* * *}$ & $0.189^{* * *}$ & $0.169^{* * *}$ & $0.142^{*}$ \\
\hline & 0.040 & 0.042 & 0.037 & 0.067 & 0.024 & 0.077 \\
\hline \multirow[t]{2}{*}{ SIZE×CM } & -0.017 & -0.015 & -0.009 & -0.058 & -0.061 & -0.059 \\
\hline & 0.042 & 0.042 & 0.043 & 0.058 & 0.056 & 0.050 \\
\hline \multirow[t]{2}{*}{$\mathrm{LEV} \times \mathrm{CM}$} & 0.030 & 0.031 & 0.039 & -0.021 & -0.001 & 0.119 \\
\hline & 0.039 & 0.040 & 0.042 & 0.043 & 0.036 & 0.098 \\
\hline \multirow[t]{2}{*}{$\mathrm{NPL} \times \mathrm{CM}$} & -0.029 & $-0.046^{*}$ & $-0.060^{* *}$ & 0.064 & -0.043 & -0.051 \\
\hline & 0.032 & 0.027 & 0.029 & 0.073 & 0.043 & 0.043 \\
\hline \multirow[t]{2}{*}{$\mathrm{NII} \times \mathrm{CM}$} & -0.016 & -0.028 & -0.029 & 0.015 & -0.017 & 0.060 \\
\hline & 0.028 & 0.027 & 0.025 & 0.017 & 0.017 & 0.066 \\
\hline Year dummy & Yes & Yes & Yes & Yes & Yes & Yes \\
\hline Adj. $R$-square & $42 \%$ & $42 \%$ & $42 \%$ & $42 \%$ & $43 \%$ & $42 \%$ \\
\hline \# of obs. & 4780 & 4780 & 4780 & 4780 & 4780 & 4780 \\
\hline
\end{tabular}




\section{Table 5. Multivariate regression results for recession and normal periods}

The table shows the multivariate results by separating recession and normal periods. We use two dummy variables in the regression, one for NBER recession periods and one for normal (expansion) periods. All the variables and their interactions are multiplied by these dummies. Definitions and exact item identifiers of the variables are given in the appendix. The variables are on a quarterly basis and cover the period 1995Q1-2016Q4.

\begin{tabular}{lccc}
\hline & Entire & Recession & Normal \\
\hline Dummy & & -0.608 & -0.271 \\
$\mathrm{CM}$ & & 0.594 & 0.388 \\
& -0.228 & -0.171 & -0.064 \\
$\mathrm{VaR}$ & 0.327 & 1.281 & 0.200 \\
& $0.122^{* *}$ & $0.291^{* * *}$ & $0.119^{* *}$ \\
$\mathrm{SIZE}$ & 0.062 & 0.070 & 0.060 \\
& $0.516^{* * *}$ & $0.830^{* * *}$ & $0.462^{* * *}$ \\
$\mathrm{LEV}$ & 0.094 & 0.146 & 0.089 \\
& -0.021 & $-0.161^{*}$ & -0.003 \\
$\mathrm{NPL}$ & 0.039 & 0.083 & 0.034 \\
$\mathrm{NII}$ & -0.042 & -0.051 & 0.022 \\
& 0.039 & 0.086 & 0.024 \\
$\mathrm{VaR} \times \mathrm{CM}$ & 0.009 & 0.036 & 0.001 \\
$\mathrm{SIZE} \times \mathrm{CM}$ & 0.046 & 0.092 & 0.050 \\
$\mathrm{~L}$ & $0.163^{* * *}$ & 0.126 & $0.103^{* * *}$ \\
$\mathrm{LEV} \times \mathrm{CM}$ & 0.040 & 0.104 & 0.032 \\
$\mathrm{NPL} \times \mathrm{CM}$ & -0.017 & -0.145 & -0.046 \\
$\mathrm{NII} \times \mathrm{CM}$ & 0.042 & 0.265 & 0.030 \\
& 0.030 & 0.354 & $0.046^{* *}$ \\
& 0.039 & 0.218 & 0.023 \\
& -0.029 & 0.661 & 0.020 \\
& 0.032 & 1.113 & 0.025 \\
& -0.016 & $-0.551^{* *}$ & -0.009 \\
& 0.028 & 0.227 & 0.029 \\
\hline
\end{tabular}


Table 6. Multivariate regression results with size and centrality as moderators

The table shows the multivariate results whit size and centrality as moderator variables. Definitions and exact item identifiers of the variables are given in the appendix. Model 1 is from Table 4 with CM1 as the centrality measure. The variables are on a quarterly basis and cover the period 1995Q1-2016Q4.

\begin{tabular}{|c|c|c|c|c|}
\hline & Model 1 & Model 2 & Model3 & Model 4 \\
\hline \multirow[t]{2}{*}{$\mathrm{CM}$} & -0.228 & 0.239 & -0.037 & $3.151^{* *}$ \\
\hline & 0.327 & 0.154 & 0.327 & 1.604 \\
\hline \multirow[t]{2}{*}{ VaR } & $0.122^{* *}$ & $-0.258^{*}$ & -0.220 & -0.225 \\
\hline & 0.062 & 0.136 & 0.146 & 0.145 \\
\hline \multirow[t]{2}{*}{ SIZE } & $0.516^{* * *}$ & $0.284^{*}$ & $0.309^{*}$ & $0.309^{*}$ \\
\hline & 0.094 & 0.173 & 0.186 & 0.186 \\
\hline \multirow[t]{2}{*}{ LEV } & -0.021 & -0.007 & -0.004 & -0.001 \\
\hline & 0.039 & 0.103 & 0.107 & 0.107 \\
\hline \multirow[t]{2}{*}{ NPL } & -0.042 & 0.038 & 0.020 & 0.017 \\
\hline & 0.039 & 0.107 & 0.114 & 0.113 \\
\hline \multirow[t]{2}{*}{ NII } & 0.009 & 0.207 & 0.186 & 0.248 \\
\hline & 0.046 & 0.196 & 0.203 & 0.218 \\
\hline \multirow[t]{2}{*}{$\mathrm{VaR} \times \mathrm{CM}$} & $0.163^{* * *}$ & & $0.083^{*}$ & $0.393^{*}$ \\
\hline & 0.040 & & 0.049 & 0.212 \\
\hline \multirow[t]{2}{*}{ SIZE×CM } & -0.017 & -0.042 & -0.022 & $-0.667^{* *}$ \\
\hline & 0.042 & 0.028 & 0.042 & 0.338 \\
\hline \multirow[t]{2}{*}{$\mathrm{LEV} \times \mathrm{CM}$} & 0.030 & & 0.019 & $-0.949^{*}$ \\
\hline & 0.039 & & 0.044 & 0.511 \\
\hline \multirow[t]{2}{*}{$\mathrm{NPL} \times \mathrm{CM}$} & -0.029 & & -0.015 & -0.351 \\
\hline & 0.032 & & 0.039 & 0.321 \\
\hline \multirow[t]{2}{*}{$\mathrm{NII} \times \mathrm{CM}$} & -0.016 & & -0.010 & -0.263 \\
\hline & 0.028 & & 0.033 & 0.251 \\
\hline \multirow[t]{2}{*}{ VaR×SIZE } & & $0.134^{* * *}$ & $0.118^{* * *}$ & $0.120^{* * * *}$ \\
\hline & & 0.038 & 0.043 & 0.042 \\
\hline \multirow[t]{2}{*}{$\mathrm{LEV} \times \mathrm{SIZE}$} & & 0.004 & 0.002 & 0.002 \\
\hline & & 0.031 & 0.033 & 0.033 \\
\hline \multirow[t]{2}{*}{ NPL× SIZE } & & -0.024 & -0.017 & -0.016 \\
\hline & & 0.038 & 0.041 & 0.041 \\
\hline \multirow[t]{2}{*}{ NII $\times$ SIZE } & & -0.045 & -0.038 & -0.053 \\
\hline & & 0.042 & 0.046 & 0.050 \\
\hline \multirow[t]{2}{*}{$\mathrm{VaR} \times \mathrm{SIZE} \times \mathrm{CM}$} & & & & -0.062 \\
\hline & & & & 0.041 \\
\hline \multirow[t]{2}{*}{$\mathrm{LEV} \times \mathrm{SIZE} \times \mathrm{CM}$} & & & & $0.200^{*}$ \\
\hline & & & & 0.109 \\
\hline \multirow[t]{2}{*}{ NPL $\times$ SIZE $\times C M$} & & & & 0.056 \\
\hline & & & & 0.059 \\
\hline \multirow[t]{2}{*}{ NII $\times$ SIZE $\times C M$} & & & & 0.052 \\
\hline & & & & 0.055 \\
\hline AdjRsquare & $42 \%$ & $43 \%$ & $44 \%$ & $44 \%$ \\
\hline
\end{tabular}




\section{Figure 1. An example of a network matrix}

The figure shows the links between the 264 firms used in the main study, based on an adjacency network matrix for last quarter of our sample, 2016Q4. Two firms are assumed to be connected from start date to the end date of each facility.

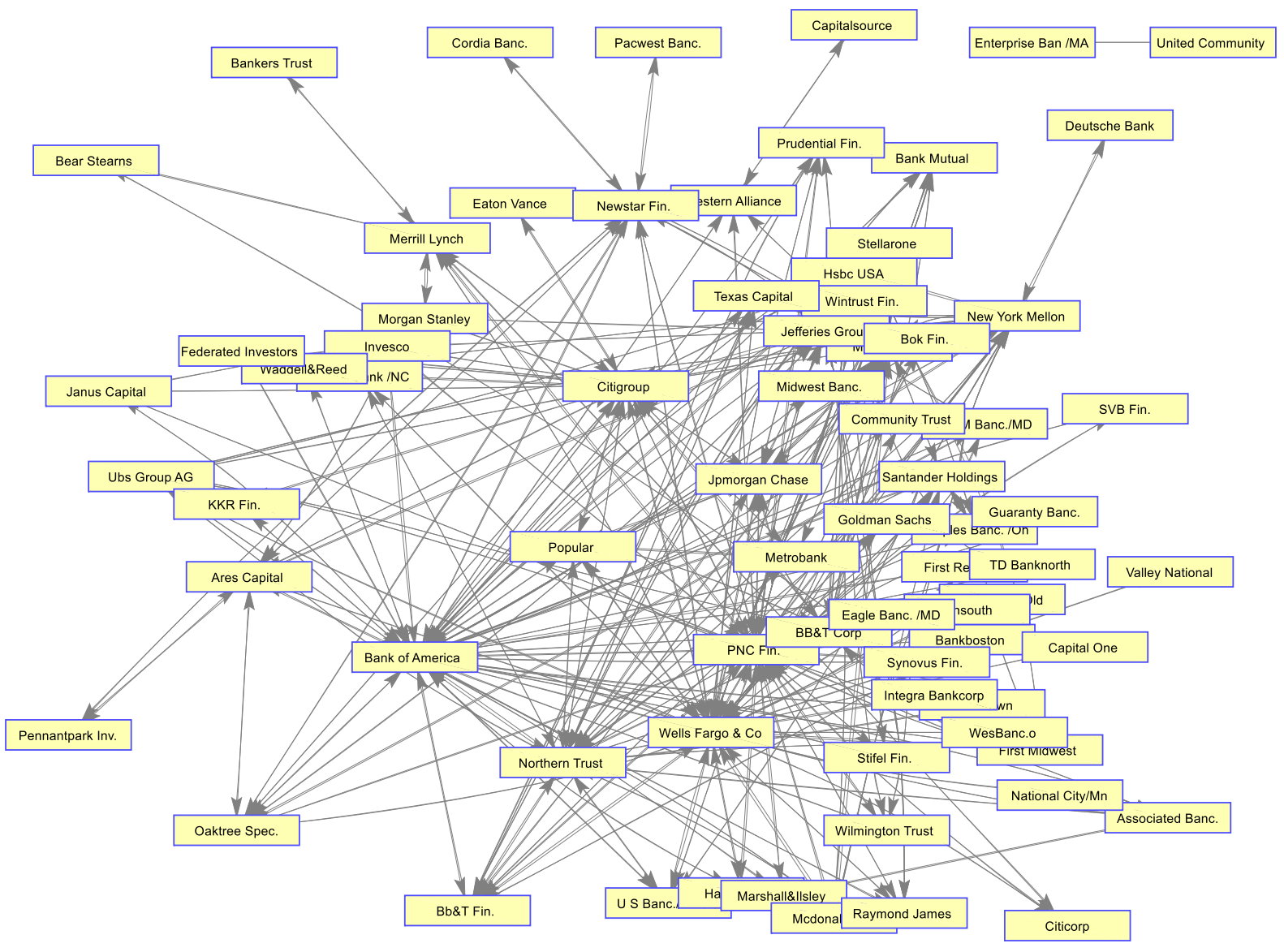




\section{Figure 2. Persistence of centrality}

The figure shows the probability of a bank remaining in top $10 \%$ of CM1 values in next quarter and in $n$-quarters, respectively, where $n$ goes from 1 to 88 , which is the total number of quarters from 1995Q1 to 2016Q4.

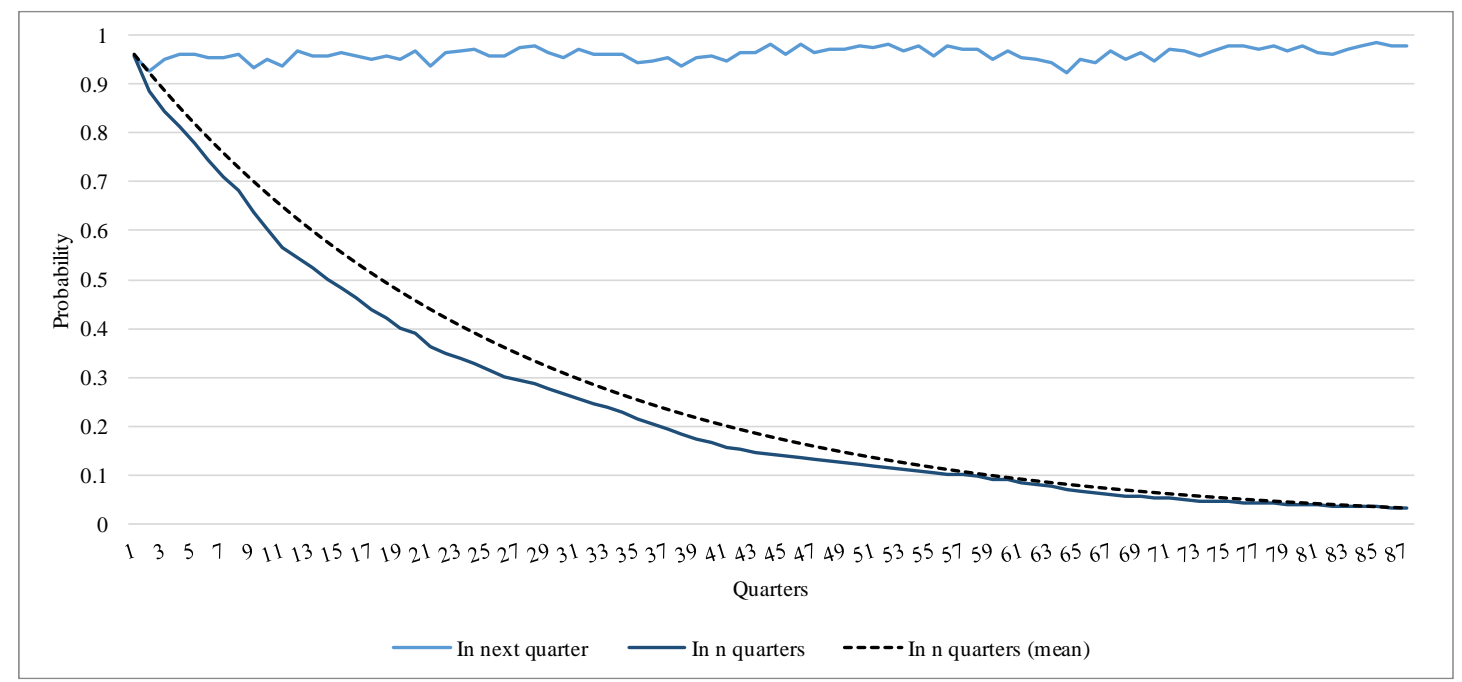




\section{Figure 3. Marginal effects of the factors}

The figure shows the estimated marginal effects and their $95 \%$ confidence interval. The estimations are based on the results given in Table 4, for the model with CM1 as the centrality measure. In each figure, the y-axis shows the marginal effect of each factor on CoVar and the $\mathrm{x}$-axis shows CM1 values. The shaded area shows CM1 values within 95\% interval around the mean.

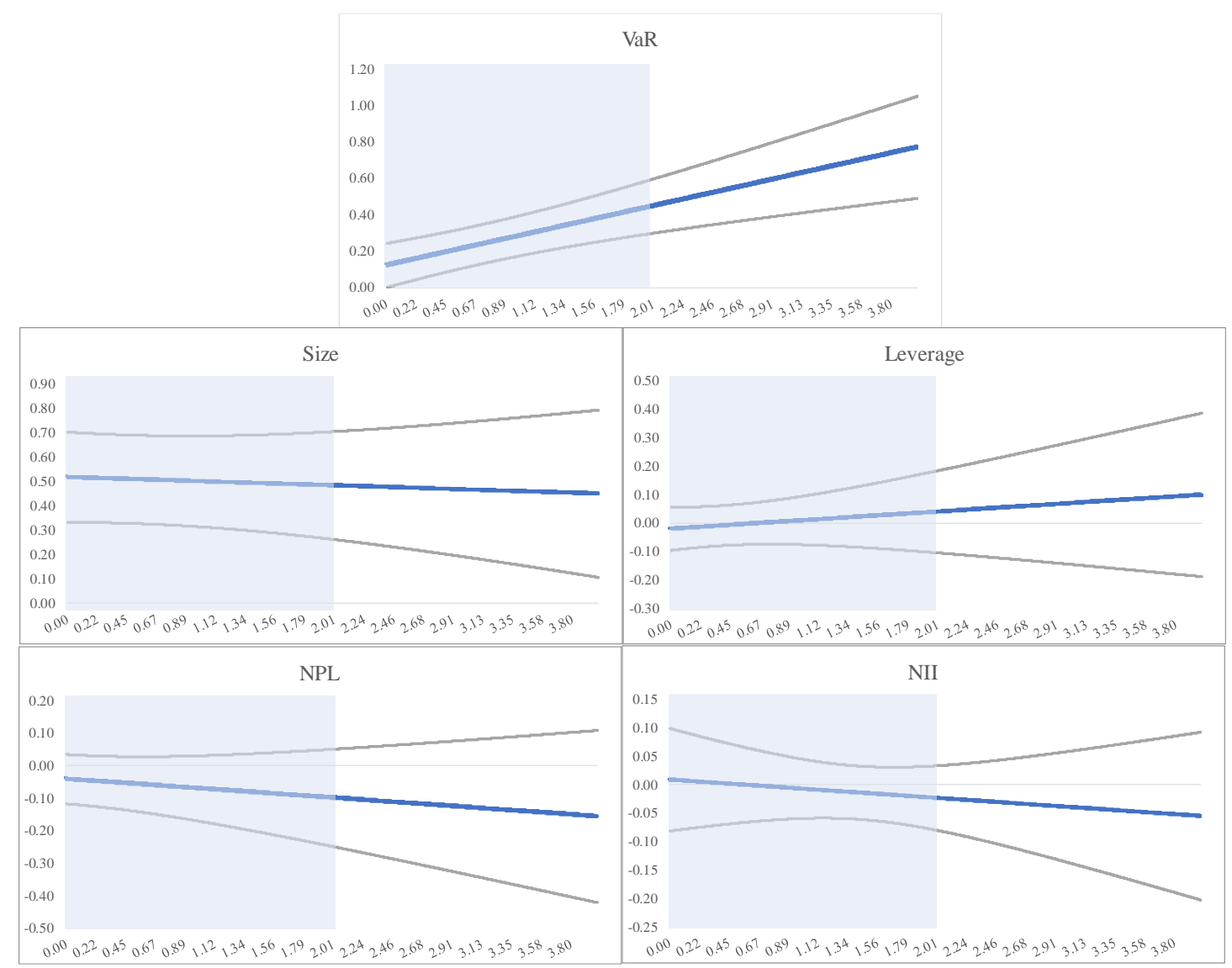




\section{Figure 4. Centrality and VaR of the largest financial institutions}

The figure shows the average (over time) centrality and average Value-at-Risk for the 15 largest financial institutions in the sample in terms or market capitalization. The red lines show the (cross-sectional) average Value-at-Risk and average centrality so that firms in the top right quadrant have above average centrality and above average Valueat-Risk.

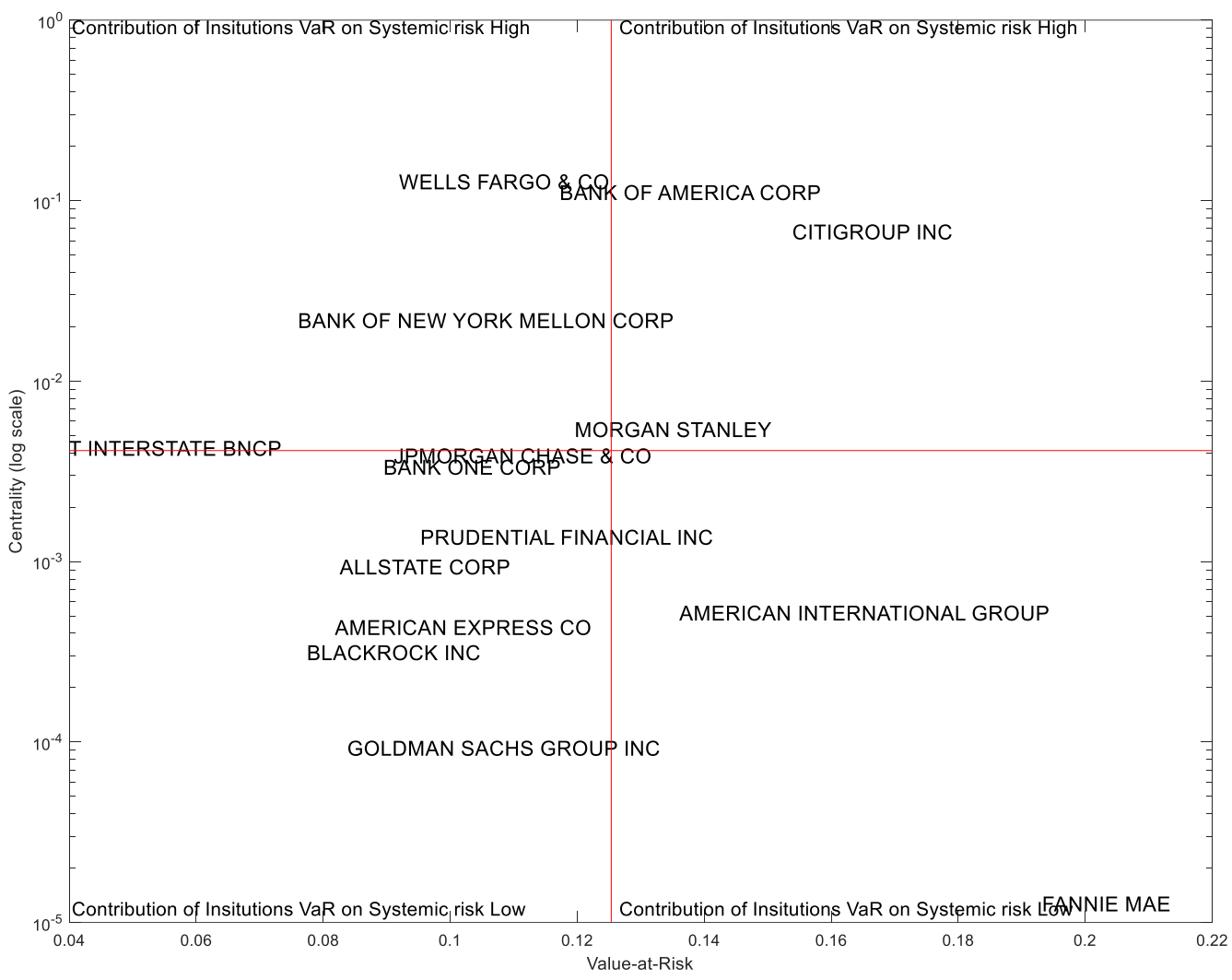


Figure 5. Marginal effects of the factors in recession and normal periods

The figure shows the estimated marginal effects for the recessions and normal periods and their 95\% confidence interval. The estimations are based on the model in Table 5. In each figure, the $\mathrm{y}$-axis shows the marginal effect of each factor on CoVar and the $\mathrm{x}$ axis shows CM1 values. The shaded area shows CM1 values within 95\% interval around the mean.

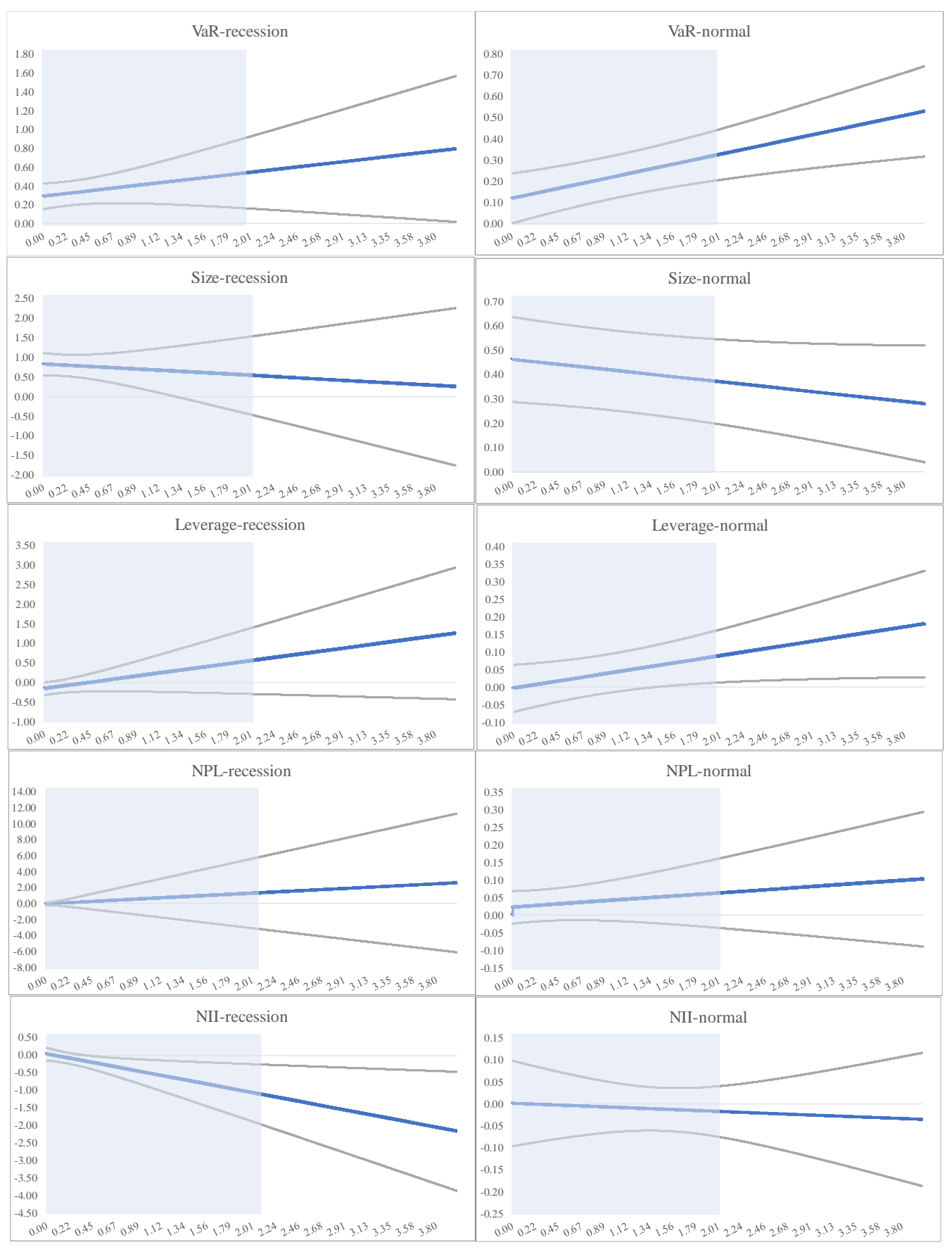


Figure 6. Marginal effects of VaR for different years

The figure shows the estimated marginal effects for different years and their 95\% confidence interval. The estimations are based on a model with CM1 as the centrality measure, where we use a dummy variable for each year to estimate the yearly parameters of CM1, VaR and their interaction terms.

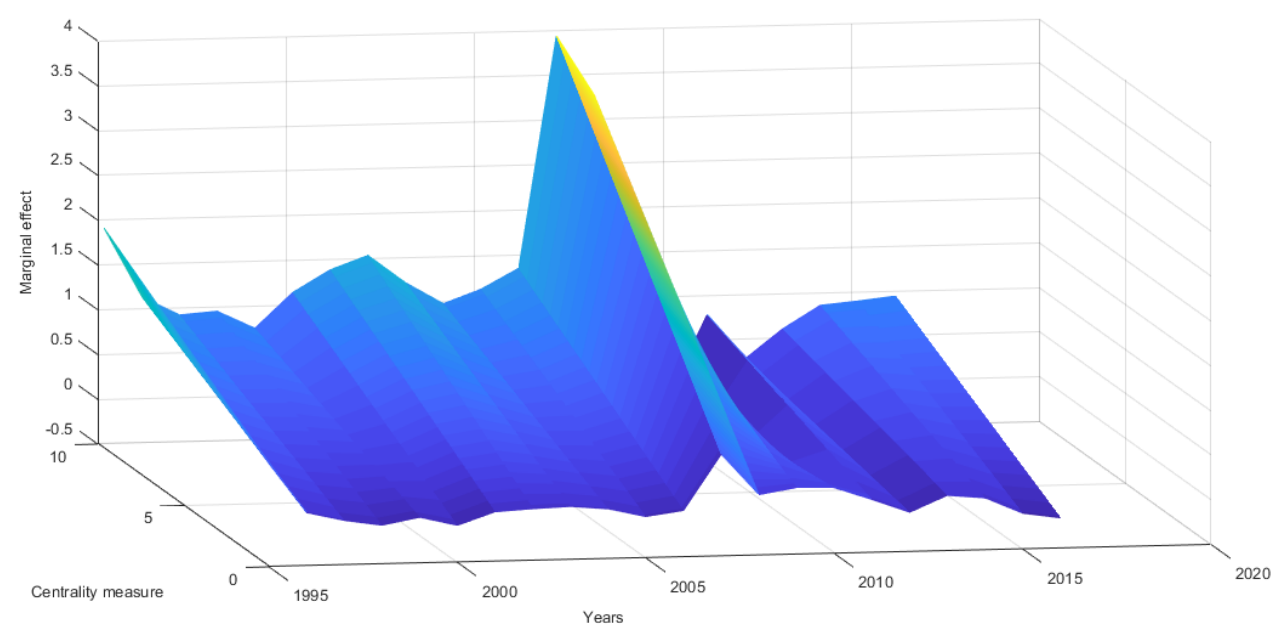




\section{APPENDIX. Variable definitions with identifiers}

Below are the different variables used in the empirical analysis and their definitions. The numbers in brackets refer to the identifier in S\&P's CapitalIQ for balance sheet and income statement variables, and to the identifier in Federal Reserve's H15 Release for selected interest rates for the macro variables, if not otherwise stated.

\begin{tabular}{|c|c|}
\hline Variable & Definition \\
\hline$\triangle \mathrm{CoVaR}$ & $\begin{array}{l}\text { The contribution to system VaR if a firm goes from being at its } \\
50 \% \mathrm{VaR} \text { (normal state) to its } 1 \% \mathrm{VaR} \text { (distressed state). }\end{array}$ \\
\hline VaR & $\begin{array}{l}\text { The maximum loss that can occur during a given time period } \\
\text { with probability q. }\end{array}$ \\
\hline$L E V$ & $\begin{array}{l}\text { Total book assets [1007] divided by the book value of equity } \\
{[1275]}\end{array}$ \\
\hline SIZE & $\begin{array}{l}\text { The natural logarithm of a firm's market capitalization [10054] } \\
\text { in million USD. }\end{array}$ \\
\hline$N P L$ & Non performing loans [3123] to total book assets [1007] \\
\hline NII & Total non-interest income [27] to total interest income [25] \\
\hline Change in the three month yield & 3 month bill rate [H15/H15/RIFSGFSM03_N.WF] \\
\hline Change in the slope of the yield curve & $\begin{array}{l}\text { Yield spread between the 10YR treasury bill } \\
\text { rate[H15/H15/RIFLGFCY10_N.WF] and the } 3 \text { month bill rate } \\
\text { [H15/H15/RIFSGFSM03_N.WF] }\end{array}$ \\
\hline TED spread & $\begin{array}{l}\text { Three month LIBOR [FRED database }{ }^{7} \text {, USD3MTD156N] } \\
\text { minus three month bill rate }[\text { H15/H15/RIFSGFSM03_N.WF] }\end{array}$ \\
\hline Change in credit spread & $\begin{array}{l}\text { Change in the credit spread between Moody's Baa-rated bonds } \\
\text { yield [H15/discontinued/RIMLPBAAR_N.WF] and the 10YR } \\
\text { treasury rate [H15/H15/RIFLGFCY10_N.WF] }\end{array}$ \\
\hline Weekly market CRSP value weighted return & CRSP value weighted market return \\
\hline $\begin{array}{l}\text { Weekly real estate sector return in excess of } \\
\text { the market financial sector return }\end{array}$ & $\begin{array}{l}\text { Average return of all firms with SIC codes } 65-66 \text { in excess of } \\
\text { financial market return SIC codes starting with } 6 \text { except for the } \\
\text { ones } 65-55 \text { obtained from K. French Data Library }\end{array}$ \\
\hline Equity volatility & $\begin{array}{l}\text { Rolling } 22 \text { day volatility of the weekly market CRSP value } \\
\text { weighted return }\end{array}$ \\
\hline
\end{tabular}

\footnotetext{
${ }^{7}$ Federal Reserve Bank of St. Louis, FRED Economic Data, https://fred.stlouisfed.org

${ }^{8}$ K. French Data Library, http://mba.tuck.dartmouth.edu/pages/faculty/ken.french/data_library.html
} 


\title{
Systemic Risk and Centrality Revisited: The Role of Interactions
}

\author{
HOSSEIN ASGHARIAN, DOMINIKA KRYGIER \& ANDERS VILHELMSSON
}

We suggest that banks contribute extensively to systemic risk only if they are both "risky" and centrally placed in the financial network. To calculate systemic risk we apply the $\Delta$ CoVaR measure of Adrian and Brunnermeier (2016) and measure centrality using detailed US loan syndication data. In agreement with our conjecture our main finding is that centrality is an important determinant of systemic risk but primarily not by its direct effect. Rather, its main influence is to make other firm specific risk measures more important for highly connected banks. A bank's contribution to systemic risk from a fixed level of Value-at-Risk is about four times higher for a bank with two standard deviations above average centrality compared to a bank with average network centrality. Neglecting this indirect moderation effect of centrality severely underestimates the importance of centrality for "risky" banks and overestimates the effect for "safer" banks.

KEYWORDS: systemic risk, network centrality, loan syndication, $\triangle$ CoVaR, quantile regression

\section{THE KNUT WICKSELL CENTRE FOR FINANCIAL STUDIES}

The Knut Wicksell Centre for Financial Studies conducts cutting-edge research in financial economics and related academic disciplines. Established in 2011, the Centre is a collaboration between Lund University School of Economics and Management and the Research Institute of Industrial Economics (IFN) in Stockholm. The Centre supports research projects, arranges seminars, and organizes conferences. A key goal of the Centre is to foster interaction between academics, practitioners and students to better understand current topics related to financial markets.

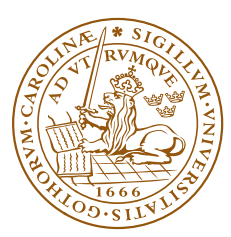

LUND UNIVERSITY

LUND UNIVERSITY

SCHOOL OF ECONOMICS AND MANAGEMENT Working paper 2019:1

school of Economics and Management

The Knut Wicksell Centre for Financial Studies 